\title{
EFEITO DA ATUAÇÃO DO PODER PÚBLICO MUNICIPAL SOBRE AS CONDIÇÕES DE VIDA DAS FAMÍLIAS EM REGIÕES PERIFÉRICAS E CENTRAL DA CIDADE DE VIÇOSA
} (MG)

\author{
R. A. BASTOS FILHO ${ }^{1}$, N. M. A. PINTO ${ }^{2}$, A. L. DE C. FIÚZA ${ }^{3}$ e D. F. DE A. REZENDE \\ Universidade Federal de Viçosa \\ reinaldinhogestorufv@hotmail.com ${ }^{1}$
}

Submetido 01/08/2019 - Aceito 14/02/2020

DOI: $10.15628 /$ holos. 2020.8849

\section{RESUMO}

O presente estudo objetivou, por meio de aplicação de 196 questionários (Survey), analisar comparativamente as realidades vividas pelas famílias residentes nas duas regiões urbanas identificadas com os mais altos índices de Segregação Socioespacial e a região urbana Centro em Viçosa-MG, buscando compreender os efeitos desse fenômeno sobre as condições de vida dessas populações. Utilizou-se do índice de Segregação Socioespacial (BASTOS FILHO, AMEIDA PINTO, CARVALHO FIÚZA E FAZITO, 2019) para selecionar as duas regiões com os mais elevados índices, Nova Viçosa e Santa Clara, e aquela com menor índice, o Centro. Calculou-se a amostra para aplicação do questionário, que traçou o perfil socioeconômico, a acessibilidade de transportes e a percepção de violência e infraestrutura do bairro. Constatou-se que há diferenças significativas entre as duas regiões com mais elevados índices de segregação socioespacial frente ao Centro em termos de investimentos em infraestrutura, taxas de furtos, roubos e homicídios, cor de pele e renda das famílias.

PALAVRAS-CHAVE: Segregação Socioespacial, Poder público, Análise comparativa, Cidade Média, Viçosa-MG.

\section{EFFECT OF THE ACTIVITIES OF THE MUNICIPAL PUBLIC POWER ON THE LIVING CONDITIONS OF FAMILIES IN PERIPHERAL AND CENTRAL REGIONS OF VIÇOA (MG)}

\begin{abstract}
This study aimed, through the application of 196 questionnaires (Survey), to comparatively analyze the realities lived by families living in the two urban regions identified with the highest rates of Socio-spatial Segregation and the urban center in Viçosa-MG, seeking to understand the effects of this phenomenon on the living conditions of these populations. The Socio-spatial Segregation Index (BASTOS FILHO, AMEIDA PINTO, CARVALHO FIÚZA AND FAZITO, 2019) was used to select the two regions with the highest rates, Nova Viçosa and
\end{abstract}

Santa Clara, and the one with the lowest index, Centro. The sample was calculated to apply the questionnaire, which traced the socioeconomic profile, accessibility of transport and the perception of violence and infrastructure in the neighborhood. It was found that there are significant differences between the two regions with the highest rates of socio-spatial segregation vis-à-vis the Center in terms of infrastructure investments, burglary, theft and homicide rates, skin color and household income.

KEYWORDS: Socio-spatial Segregation, Government, Comparative Analysis, Middle City, Viçosa-MG. 


\section{INTRODUÇÃO}

A Segregação Socioespacial é percebida por Maricato (2000) como a expressão maior da exclusão social e se configura em pontos de pobreza generalizada, sendo percebida pela dificuldade de acesso a serviços e equipamentos coletivos, pelas menores oportunidades de emprego e profissionalização, pelos altos índices de violência, pela discriminação social contra mulheres e crianças etc. Ou seja, a condição de vulnerabilidade depende ao mesmo tempo das oportunidades existentes e dos ativos disponíveis para acessá-las (KAZTMAN; FILGUEIRAS, 2006).

Nesse sentido, Villaça (2001) complementa dizendo que a segregação é um processo no qual distintas classes ou camadas sociais tendem a se concentrar cada vez mais em diferentes regiões ou conjunto de bairros. Da mesma forma, como diz Santos (1993), as classes mais abastadas transformam seletivamente os lugares de acordo com seus interesses, se instalando em locais centrais e com maiores infraestruturas. Esse seria o mais conhecido padrão de segregação, o de centro versus periferia. Neste modelo, o centro apresenta acesso a serviços urbanos, seja público ou privado, ocupado pelas camadas de mais alta renda; e a periferia, ao contrário, subequipada e longínqua, é ocupada pelas camadas de mais baixa renda (VILLAÇA, 2001), acabando por criar uma dualidade entre cidade dos ricos e cidade dos pobres, ou mesmo entre cidade legal e cidade ilegal (BONDUKI, 2010).

Considerando então a ideia de que o "espaço importa" (FLORES, 2006; TORRES, FERREIRA, GOMES, 2005) nas condições de inserção e reprodução social das famílias, torna-se relevante conhecer não somente a magnitude do fenômeno da segregação socioespacial, mas também as suas principais características em termos de grupos socioeconômicos envolvidos, características demográficas, percepção em relação à infraestrutura e violência, perfil migratório etc.

Assim sendo, este trabalho se inicia a partir da oportunidade dada pela elaboração do índice de Segregação Socioespacial (ISSE) ${ }^{1}$, onde foi possível identificar as duas regiões urbanas de planejamento na cidade de Viçosa que são, hoje, as mais segregadas socioespacialmente e comparativamente à região Centro, que não apresenta Segregação Socioespacial. Contudo, por abarcar uma análise geral do espaço urbano, onde se buscou mostrar o processo de urbanização e segregação socioespacial, as análises realizadas no trabalho citado não conseguiram descrever as realidades, de forma detalhada, de cada uma dessas três regiões, perspectiva que se busca construir nesse momento. Assim, com base na percepção dos chefes de família, eleitos como informantes-chave, buscou-se descrever como se materializa o fenômeno da Segregação Socioespacial, que também é causada pela forma como o poder público direciona seus investimentos na cidade (LOJKINE, 1981; VETTER; MASSENA, 1982; PINÇON-CHARLOT et al, 1986; CASTELLS, 1983; SCHAEFFER, 2003) no tocante à condição de vida, no cotidiano das famílias que vivem nessas duas regiões mais segregadas socioespacialmente (Região Nova Viçosa e Santa

\footnotetext{
${ }^{1}$ Essa análise está associada ao artigo publicado na edição Jul/Set, 2019, na Revista Interações: BASTOS FILHO, R. A; ALMEIDA PINTO, N. M.; CARVALHO FIÚZA, A. L; FAZITO. D. A elaboração de um índice de segregação socioespacial como ferramenta de gestão e análise do espaço urbano de Viçosa-MG, INTERAÇÕES, Campo Grande, MS, v. 20, n. 3, p. 707-723.
} 
Clara), em comparação ao grupo de controle (a região Centro, apresentada como a melhor classificada em termos de segregação socioespacial).

Para tanto, tal pesquisa, caracterizada como um estudo de caso com abordagem qualitativa e caráter descritivo, e utilizando-se da amostragem probabilística por meio de aplicação de 196 questionários (Survey) de forma aleatória nas três regiões de planejamento (Nova Viçosa, Santa Clara e Centro), objetivou-se analisar de forma comparativa as condições de vida das famílias residentes nessas três regiões urbanas de planejamento em Viçosa-MG, descrevendo os efeitos do fenômeno da segregação socioespacial (a partir da atuação e investimentos do poder público municipal) nas condições de vida dessas populações. Tal análise leva em consideração o perfil socioeconômico, a condição da infraestrutura do bairro, a acessibilidade ao transporte, e por fim, a percepção dos chefes de família quanto à sensação de violência e o acesso a serviços públicos. Tais análises permitiram perceber as diferenças e semelhanças que os efeitos da atuação do poder público local representam no cotidiano das famílias dessas regiões.

\section{O CONCEITO DE SEGREGAÇÃO SOCIOESPACIAL E SEU ÍNDICE (ISSE) EM VIÇOSA- MG}

Frey e Duarte (2006) dizem, grosso modo, que a segregação é analisada geralmente como sendo um agrupamento de humanos desfavorecidos no âmbito de um conjunto social, seja por questões raciais, religiosas ou econômicas (esta última com destaque no Brasil). Além disso, esse fenômeno pode ser percebido também como sendo a exclusão de um grupo de pessoas do direito à cidade e, nesse sentido, não importa se a formação de territórios segregados se remeta às periferias, com pouca ou nenhuma infraestrutura, ou aos centros urbanos em processo de esvaziamento de vitalidade socioeconômica.

Contudo, para Sposito (2016), no que se refere ao conceito de segregação socioespacial isso se aplica quando as formas de diferenciação causam uma separação espacial radical, e implicam quebra da região segregada e do conjunto do espaço urbano, gerando consequentemente uma dificuldade nas relações e nas articulações que movem a vida na cidade.

No Brasil, os primeiros indícios de segregação surgiram no final do século XIX, mais precisamente a partir da década de 1880, com a "diversificação das funções e o aparecimento, ao lado do velho centro, de bairros operários e de bairros residenciais finos" (MATOS, 1958, p. 89). Para Bonduki há, no elemento classe, um forte determinante para as formas de ocupação do espaço urbano. Nas suas palavras:

O problema da habitação popular no final do século XIX é concomitante aos primeiros indícios de segregação espacial. Se a expansão da cidade e a concentração de trabalhadores ocasionou inúmeros problemas, a segregação social do espaço impedia que os diferentes estratos sociais sofressem da mesma maneira os efeitos da crise urbana, garantindo à elite áreas de uso exclusivo, livres da deterioração, além de uma apropriação diferenciada dos investimentos públicos (BONDUKI, 1998, p.20). 
Milton Santos (1993, p.96), por sua vez, trabalha o conceito de Sítio Social para explicar esse processo de segregação e entender a produção dos bairros residenciais feitos pela e para a burguesia ao longo do processo de urbanização brasileira. Nesse sentido, Villaça (2001) complementa dizendo que a segregação é um processo no qual distintas classes ou camadas sociais tendem a se concentrar cada vez mais em diferentes regiões ou conjunto de bairros. Ou seja, como diz Santos (1993), as classes mais abastadas transformam seletivamente os lugares de acordo com seus interesses, se instalando em locais centrais e com maiores infraestruturas. Esse seria o mais conhecido padrão de segregação, o de centro versus periferia. Neste modelo, o centro apresenta acesso a serviços urbanos, sejam eles públicos ou privados, e é ocupado pelas camadas de mais alta renda, enquanto a periferia, subequipada e longínqua, é ocupada pelas camadas de mais baixa renda (VILLAÇA, 2001) acabando por criar uma dualidade entre cidade dos ricos e cidade dos pobres, ou mesmo entre cidade legal e cidade ilegal (BONDUKI, 2010). Assim, a localização da moradia (em relação ao centro) é um indicador relevante. Aquelas localidades mais afastadas ficam prejudicadas também nesse sentido, visto que se torna necessário o deslocamento de pessoas ou produtos entre locais de moradias e os de produção e consumo. Ou seja, além da separação espacial, a segregação também é entendida como separação social (VILLAÇA, 2001, 2011; CALDEIRA, 2000).

Do Lago (2002) e Maricato (1997, 2000 e 2013), de maneira complementar, falam que a segregação, além dessa separação social, também significa desigualdade de acesso. Percebe-se essa desigualdade de acesso quando temos as periferias como locais afastados do centro, habitados pela população trabalhadora, desprovidos tanto de serviços quanto de equipamentos públicos e marcados por condições sociais e urbanas muito precárias (BONDUKI e ROLNIK, 1982). Essas periferias, pobres e afastadas do centro, frequentemente registram um padrão de violência diferenciado, ou seja, apresentam as maiores taxas de homicídios em contraposição às áreas centrais, que, por sua vez, registram altas taxas de roubos e furtos, uma vez que são locais de maior dinamismo econômico e comercial (CALDEIRA, 2000; IZUMINO e NEME, 2002; LIMA, 2004; WEISELFISZ, 2013; CARVALHO e SANTOS, 2017).

Para tanto, utilizou-se o índice de segregação socioespacial (ISSE) elaborado por Bastos Filho, Almeida Pinto, Carvalho Fiúza e Fazito (2019) como ferramenta para seleção das 3 regiões urbanas de planejamento utilizadas neste trabalho.

Tabela 1: Índice de Segregação Socioespacial de Viçosa-MG²

\begin{tabular}{|c|c|c|c|}
\hline \multicolumn{4}{|c|}{$\begin{array}{c}\text { Índice }{ }^{3} \text { de Segregação Socioespacial no Município de Viçosa por região urbana } \\
\text { de Planejamento (ISSE) }\end{array}$} \\
\hline Regiões & ISSE & Regiões & ISSE \\
\hline 1. Centro ${ }^{4}$ & 0,078 & 7. Nova Era & 0,450 \\
\hline
\end{tabular}

\footnotetext{
2 Para maiores informações de sua elaboração, consultar artigo de BASTOS FILHO, R. A; ALMEIDA PINTO, N. M.; CARVALHO FIÚZA, A. L; FAZITO. D. A elaboração de um índice de segregação socioespacial como ferramenta de gestão e análise do espaço urbano de Viçosa-MG. Revista Interações, 2019.

${ }^{3} \mathrm{O}$ índice varia de 0,0 a 1,0 sendo que, quanto mais próximo de 1,0 mais segregada socioespacialmente é a região urbana de planejamento.
} 


\begin{tabular}{|l|l|l|c|}
\hline 2. Fátima & 0,311 & 8. Passos & 0,456 \\
\hline 3. Lourdes & 0,311 & 9. Silvestre & 0,456 \\
\hline 4. Santo Antônio & 0,378 & 10. Amoras & 0,556 \\
\hline 5. Acamari & 0,417 & $\mathbf{1 1 . ~ S a n t a ~ C l a r a ~}$ & $\mathbf{0 , 6 3 6}$ \\
\hline 6. Bom Jesus & 0,442 & $\mathbf{1 2 . ~ N o v a ~ V i c ̧ o s a ~}$ & $\mathbf{0 , 6 8 1}$ \\
\hline
\end{tabular}

Fonte: Elaboração própria (2018) com base em dados de Cruz (2014), Viação União (2016), Google Maps (2017), Plano Diretor de Viçosa (S.d), Blog Saúde Viçosa (S.d) e Portal da Saúde - PMV (S.d)

A partir dessa perspectiva teórica, se torna relevante conhecer não somente a magnitude do fenômeno da segregação socioespacial, mas também as suas principais características em termos dos grupos socioeconômicos envolvidos, suas características demográficas, percepção em relação à infraestrutura e violência etc. Uma vez que, como consideram Flores (2006) e Torres, Ferreira, Gomes, (2005), o "espaço importa" nas condições de inserção e reprodução social das famílias.

\section{PROCEDIMENTOS METODOLÓGICOS}

Para essa pesquisa foram utilizados a observação in loco, dados primários e secundários. Assim sendo, para subsidiar e dar representatividade à população em estudo, quantificando assim o número de sujeitos a serem entrevistados, foi realizado o método de amostragem probabilística, que, segundo Babbie (1999, p. 125), tem como "finalidade última [...] selecionar um conjunto de elementos de uma população de tal forma que descrições destes elementos (estatísticas) descrevam com precisão a população total da qual foram selecionados".

Dentro da amostragem probabilística utilizou-se a amostragem por conglomerado, que é a mais adequada a este estudo, uma vez que proporciona mais confiabilidade às reais situações dos moradores das regiões segregadas socioespacialmente, já que agrupam, em cada aglomerado, características semelhantes do grupo entrevistado.

Para composição da amostra e escolhas dos sujeitos a serem entrevistados foram realizadas três etapas durante a pesquisa de campo: divisão de cada uma das três regiões em dois aglomerados; cálculo da amostra a partir do número de domicílios presentes em cada região de planejamento, com base em dados do retrato social 5 realizado por Cruz (2014); e, por fim, a aplicação dos questionários.

Após realização do cálculo amostral, foram aplicados 65 questionários, tanto em Nova Viçosa quanto em Santa Clara, e 66 aplicados no Centro. Desta forma, foi possível gerar uma grande quantidade de informações que serão descritas e discutidas no próximo tópico. Em outras palavras, as informações aqui geradas permitiram descrever os perfis das famílias e as condições de vida desses moradores nas diferentes regiões urbanas no que se refere aos seguintes âmbitos: socioeconômico, acessibilidade, infraestrutura e violência.

\footnotetext{
${ }^{4}$ A região de planejamento Centro se encontra com 0,078 por dois fatores principais: ser a referência central e comercial da cidade e por abarcar quase todos os indicadores na faixa ideal.
} 


\section{RESULTADOS E DISCUSSÕES}

As primeiras discussões e resultados giraram em torno de uma análise comparativa entre os perfis socioeconômicos das três regiões selecionadas. Tais informações permitem entender as semelhanças e diferenças das populações que compõem cada grupo regional. Na composição dessa variável, foram associados os indicadores: cor de pele e renda.

Predominantemente, nas duas regiões categorizadas com os mais elevados índices de segregação socioespacial prevalecem chefes de família com as cores de pele preta e parda. Sendo que em Nova Viçosa, o número de pretos (37\%) é maior que em Santa Clara (24\%). O fenômeno da negritude associado à região segregada socioespacialmente fica mais evidente quando somados os percentuais de pretos e pardos, que segundo o IBGE (PNAD, 2015), formam o grupo de negros. Neste somatório, identifica-se que os negros compõem $79 \%$ dos chefes de família em Nova Viçosa e $72 \%$ dos de Santa Clara. Por outro lado, na região Centro, o percentual de pessoas que se identifica como de pele branca chegou a 77\%. Em outras palavras, fica evidente que a segregação racial/étnica também é um indicador muito forte na Segregação Socioespacial de Viçosa (MG). Dados do mapa racial, criado pela Post Advertising Technology Agency (PATA) ${ }^{5}$, reforçam essa forte relação do índice de segregação socioespacial e segregação racial no município, conforme mostram a Figura 1 e Tabela 2, abaixo.

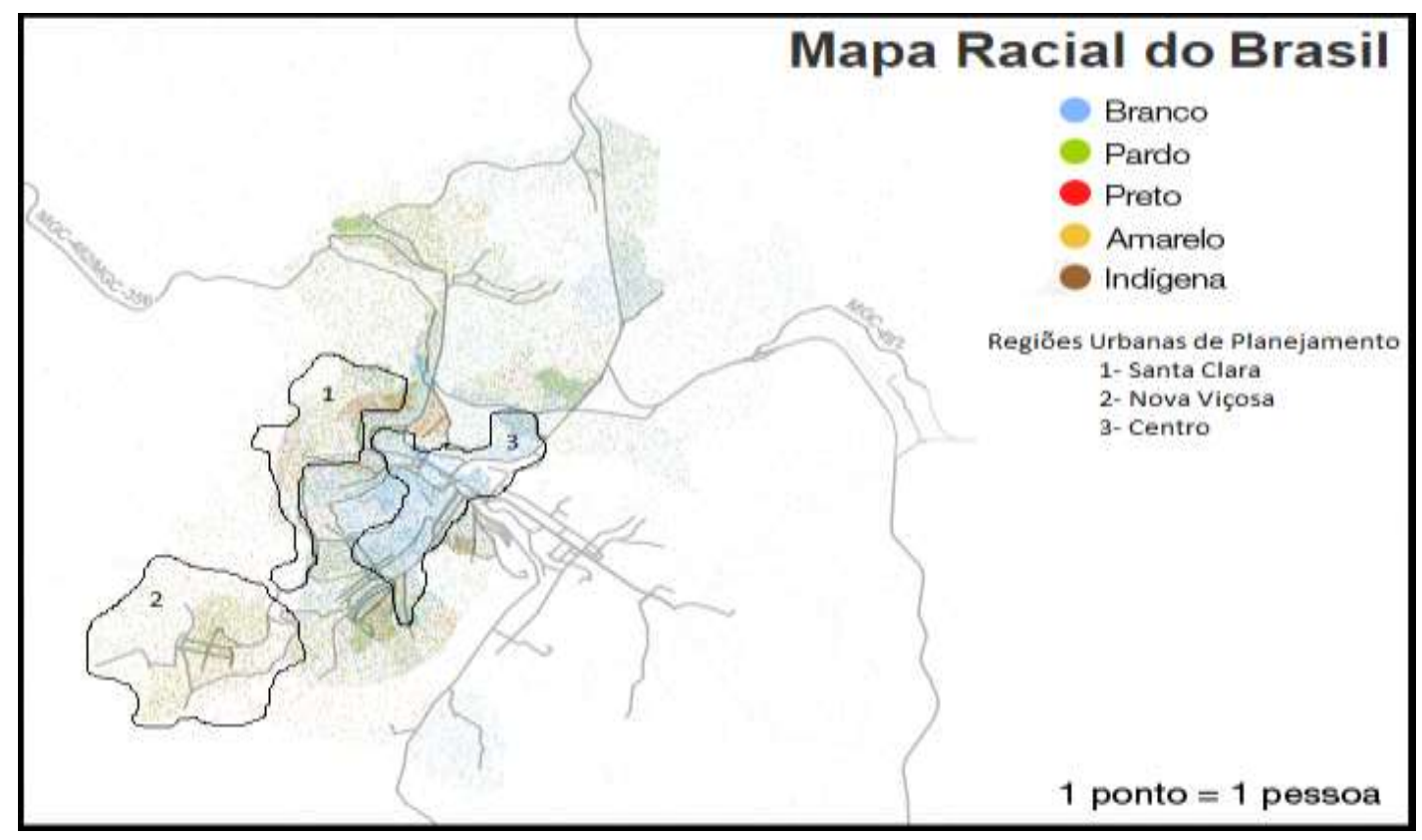

Figura 1: Mapa Racial de Viçosa (MG)

Fonte: Post Advertising Technology Agency (PATA), 2018.

No que se refere à renda, percebe-se que a região central apresenta as maiores rendas entre as três regiões. Entretanto, a de Santa Clara é superior à de Nova Viçosa, tanto na análise da renda

\footnotetext{
${ }^{5}$ A elaboração desse mapa, teve sua inspiração e a base do código utilizado para gerar o mapa de um ex-pesquisador do Cooper Center for Public Service da University of Virginia, e autor de um mapa racial dos Estados Unidos, chamado Dustin Cable. Ele, por sua vez, foi inspirado por Brandon Martin-Anderson do MIT Media Lab, e Eric Fischer, mapmaker/programador.
} 
média familiar, quanto nas análises da renda média individual e da maior renda familiar (Tabela 2). Quando analisamos o número de indivíduos que possuem uma renda mensal de até um salário mínimo ${ }^{6}$, observamos que grande parte dos chefes de família recebe - no máximo - essa quantia. Ou seja, estes indivíduos em Nova Viçosa representam um total de $78 \%$ da população, e em Santa Clara de 62\%. Ao nos remetermos à renda familiar, estes percentuais se tornam mais baixos. Assim, em Nova Viçosa, o percentual de famílias que possuem renda de até um salário mínimo é de $29 \%$ e, em Santa Clara, de $25 \%$ - resultado que relaciona a alta incidência de famílias vivendo com baixa renda, agravando este cenário.

Dentro desses grupos, observa-se também, em Nova Viçosa, 34\% das famílias em situação de pobreza e outras $12,30 \%$ em situação de extrema pobreza. Mesmo com percentuais menores, a realidade em Santa Clara também é grave: $21,5 \%$ das famílias são consideradas pobres e outras $12,30 \%$ se encontram em grau de extrema pobreza.

Tabela 2: Perfil Socioeconômico dos Chefes de Família nas Regiões Nova Viçosa, Santa Clara e Centro.

\begin{tabular}{|c|c|c|c|c|c|}
\hline \multicolumn{3}{|c|}{ Regiões Urbanas de Planejamento } & Nova Viçosa & Santa Clara & Centro \\
\hline \multicolumn{3}{|c|}{ População total das Regiões Urbanas de Planejamento } & 5.214 & 5.621 & 7.197 \\
\hline \multicolumn{2}{|c|}{ População } & $\begin{array}{l}\text { № total de } \\
\text { Domicílios }\end{array}$ & 1.442 & 1.548 & 2.513 \\
\hline \multicolumn{2}{|c|}{ Amostra } & $\begin{array}{l}\text { Entrevistados } \\
\text { (Chefes de Família) }\end{array}$ & 65 & 65 & 66 \\
\hline Categorias & Subcategorias & Indicadores & & & \\
\hline \multirow{12}{*}{$\begin{array}{c}\text { Perfil } \\
\text { Socioeconômico }\end{array}$} & \multirow{5}{*}{ Cor } & Indígena & $0 \%$ & $2 \%$ & $0 \%$ \\
\hline & & Amarela & $4 \%$ & $3 \%$ & $0 \%$ \\
\hline & & Branca & $17 \%$ & $23 \%$ & $77 \%$ \\
\hline & & Preta & $37 \%$ & $24 \%$ & $0 \%$ \\
\hline & & Parda & $42 \%$ & $48 \%$ & $23 \%$ \\
\hline & \multirow{7}{*}{ Renda } & $\begin{array}{l}\text { Chefes de família } \\
\text { com renda individual } \\
\text { de até } 1 \text { salário } \\
\text { mínimo }(R \$ 937,00)\end{array}$ & $78 \%$ & $62 \%$ & $5 \%$ \\
\hline & & \begin{tabular}{|ll}
$\begin{array}{l}\text { Maior } \\
\text { individual }\end{array}$ & renda \\
\end{tabular} & $R \$ 4.900,00$ & $R \$ 4.600,00$ & $R \$ 25.000,00$ \\
\hline & & $\begin{array}{ll}\text { Menor } & \text { renda } \\
\text { individual } & \end{array}$ & $R \$ 0,00$ & $R \$ 0,00$ & $R \$ 0,00$ \\
\hline & & $\begin{array}{ll}\text { Renda média } \\
\text { individual }\end{array}$ & $\mathrm{R} \$ 950,12$ & $\mathrm{R} \$ 1.379,30$ & $R \$ 5.022,76$ \\
\hline & & $\begin{array}{l}\text { Renda familiar de } \\
\text { até } 1 \text { salário mínimo } \\
(\mathrm{R} \$ 937,00)\end{array}$ & $29 \%$ & $25 \%$ & $0 \%$ \\
\hline & & Maior renda familiar & $R \$ 6.400,00$ & $\mathrm{R} \$ 8.100,00$ & $\mathrm{R} \$ 40.000,00$ \\
\hline & & Menor renda familiar & $\mathrm{R} \$ 0,00^{7}$ & $\mathrm{R} \$ 100,00$ & $\mathrm{R} \$ 1.000,00$ \\
\hline
\end{tabular}

\footnotetext{
${ }^{6}$ O salário mínimo federal no ano de 2017 era de $\mathrm{R} \$ \mathrm{R} \$$ 937,00.

${ }^{7}$ Indivíduo que vive sozinho e sobrevive com base em ajudas
} 
Fonte: Elaboração própria com base em dados da pesquisa, 2019.

Na análise comparativa da renda, com base no IBGE (2015), esses dados das regiões periféricas de Viçosa-MG são piores, inclusive, que os dados nacionais, o que revela o alto grau de vulnerabilidade das famílias que vivem nessas regiões. Tanto em Nova Viçosa quanto em Santa Clara o número de famílias em situação de extrema pobreza está acima da média brasileira, que registrou em 2015 uma porcentagem de 9,2\% de famílias em tal situação.

No que se refere à acessibilidade de transportes, para Rodrigues de Sousa (2005), precisamos estar em constante movimento, seja para trabalhar, ir à escola, igreja, lazer ou fazer compras. E isso passou a ser elemento essencial aos cidadãos de uma cidade. Para o autor (2005, p.120), "os motivos para os usos dos sistemas de circulação são os mais variados, no entanto boa parte da população se movimenta com mais dificuldade devido às más condições financeiras".

De acordo com Vasconcelos (2001), para se entenderem os padrões de deslocamento, deve-se compreender o padrão familiar. Assim, buscou-se investigar o meio de transporte utilizado e o tempo gasto para se locomover, tanto no acesso ao centro quanto para os locais de trabalho dos chefes de família. Essa análise permitiu descrever o impacto da acessibilidade no contexto de segregação socioespacial dos chefes de família nas regiões estudadas.

Os dados revelam que o tipo de transporte utilizado diariamente pelas pessoas é diferente nas duas regiões urbanas. Enquanto prevalece o ônibus e a motocicleta em Nova Viçosa, em Santa Clara a prioridade é o deslocamento a pé, seguido do deslocamento por ônibus. As entrevistas nos ajudam a entender essas diferenças, uma vez que nos relatos dos chefes de família de Nova Viçosa, a distância era o fator que determinava a escolha por ir de motocicleta ou de ônibus. Por outro lado, os relatos em Santa Clara revelam que fazer a descida do morro não era problema para se fazer a pé. Contudo, na volta era necessário a utilização do transporte público (ônibus). Dados do Google Maps (2017) revelam que a distância em quilômetros entre a região Nova Viçosa e o Centro é de $2,8 \mathrm{~km}$ e de Santa Clara ao mesmo ponto central é $1,8 \mathrm{~km}$, o que revela um fator que determina as diferentes formas de se locomover no espaço urbano: a distância e, ou, proximidade em relação ao centro. No dia-a-dia dos moradores, a menor distância da região de Santa Clara possibilita aos moradores a escolha pela locomoção a pé, o que é mais limitante em se tratando dos moradores de Nova Viçosa. Estes últimos ficam circunscritos ao transporte coletivo, o que sempre impõe a obrigatoriedade de arcar com os custos desse deslocamento, que devem ser subtraídos, ainda mais, dos poucos rendimentos (salário).

Além do custo financeiro, o tempo gasto para se locomover da região até o Centro, em todas as modalidades de transporte, é maior para os chefes de família que vivem em Nova Viçosa. A forma de locomoção para ir ao trabalho acompanha a mesma tendência descrita acima, prevalecendo em Nova Viçosa o ônibus (18 pessoas dentre as entrevistadas) e a motocicleta (11 pessoas dentre as entrevistadas), e em Santa Clara, o ir a pé (12 pessoas dentre as entrevistadas) está em primeiro lugar e o ônibus (11 pessoas dentre as entrevistadas), em segundo. 
Estes dados evidenciam que locais com maior índice de segregação, principalmente pelo seu afastamento dos locais de comércio e trabalho, afetam negativamente as populações mais pobres: pela distância, que acaba por tomar mais tempo em deslocamento; e pela onerosidade que o valor da passagem de ônibus trás, deixando ainda mais vulneráveis essas famílias.

Quanto aos dados de violência, os estudos de Lima, (2004), Weiselfisz (2013) e Carvalho e Santos (2017), mostram que tal segmento apresenta um perfil diferente no espaço da cidade, onde furtos e roubos acontecem em maior número na região central e os homicídios acontecem em maior número em regiões pobres. Ou seja, as regiões ricas são visadas pelo poder econômico que oferecem, enquanto as periferias marcadas pelos crimes de homicídio.

Assim, nesta categoria, discutiu-se e analisou-se a violência percebida pelos chefes de famílias, ou seja, as percepções em relação à sensação de insegurança. Além disso, foi exposto um mapa das diferentes formas de violências (homicídios, furtos e roubos) registradas pela polícia civil de Viçosa no ano de 2016 para dialogar com os dados levantados por meio da aplicação do questionário. A partir daí, buscou-se analisar a percepção de violência nas regiões segregadas, comparativamente à região de controle, o Centro.

Observa-se que $38 \%$ dos chefes de família em Nova Viçosa percebem o risco de roubo na região como médio. Já em Santa Clara, a percepção que prevaleceu foram os $43 \%$ que categorizam a região como de baixo risco de roubo. Assim, os chefes de família que vivem em Santa Clara acreditam ter maior segurança em relação ao risco de roubo no próprio bairro.

Por outro lado, os chefes de família das duas regiões segregadas, Nova Viçosa e Santa Clara, acreditam que outros locais da cidade oferecem maior risco em relação ao roubo do que a região que vivem. Ou seja, em Nova Viçosa, $43 \%$ dos chefes de família responderam que outros locais da cidade oferecem alto risco de roubo, enquanto em Santa Clara, mais pessoas acreditam que esse risco é alto: $61 \%$ desses indivíduos pontuaram outros locais da cidade como de alto risco de roubo.

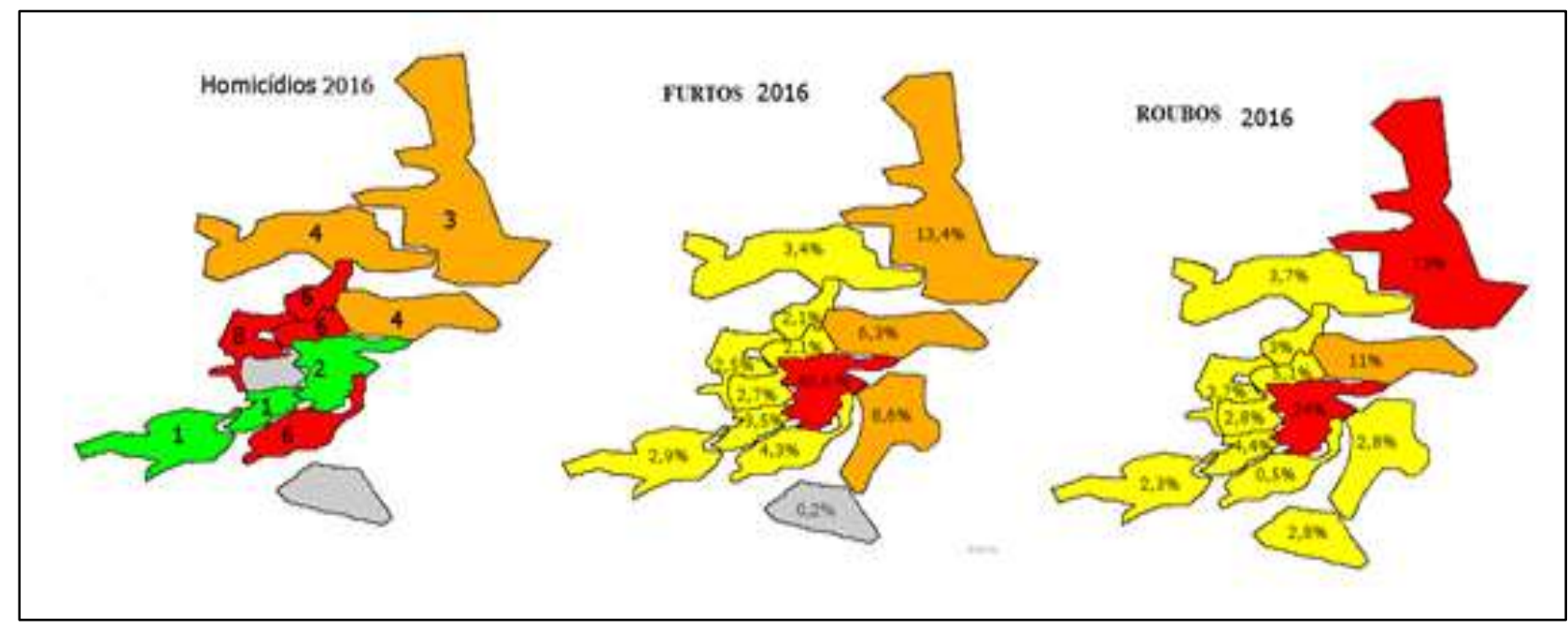

Figura 2: Número de homicídios e porcentagens de furtos e roubos por região urbana de planejamento em Viçosa, Minas Gerais, em 2016. Fonte: Elaborado com base em dados da Delegacia de Polícia Civil de Viçosa-MG, 2016. 
Quando se compara os dados registrados pela polícia civil com os estudos citados, e as percepções dos chefes de família, observa-se que em termos de roubos e furtos as percepções de segurança na região de planejamento são comprovadas pelos números da polícia. De fato, são baixos os registros dessas violências nas duas localidades mais segregadas se comparado à região central. Entretanto, quando nos remetemos aos homicídios, percebe-se que em 2016 a região Santa Clara foi a que registrou o maior número na cidade, confirmando o padrão que os estudos de Lima, (2004), Weiselfisz (2013) e Carvalho e Santos (2017) já encontraram: regiões ricas (centrais) apresentam maior incidência de furtos e roubos, e regiões periféricas, por outro lado, maior registro de homicídios.

Durante o período de aplicação dos questionários nas duas regiões, foram realizadas, ao mesmo tempo, observações em relação à infraestrutura e serviços presentes nas regiões de planejamento. Para tanto, tomou-se os seguintes indicadores: presença de calçamento nas ruas (asfalto, paralelepípedo, pedra fincada ou terra batida), presença de guias (meio fio) e qualidade das ruas. Além disso, foi perguntado aos chefes de família, qual a percepção que tinham em relação: à iluminação pública, ao acesso a serviços de água e de esgoto e às formas de recolhimento do lixo (recolhimento pelo Serviço Autônomo de Água e Esgoto de Viçosa - SAAE Viçosa e cuidados dos próprios moradores).

Em Nova Viçosa, região com o maior índice de Segregação Socioespacial, 55\% dos chefes de família dizem que no trajeto que percorrem no dia-a-dia há postes de luz sem iluminação, assim como no Centro (55\%). Em Santa Clara, esse número é menor: 31\% dos chefes de família relataram que há vias sem iluminação no trajeto que percorrem. Estes dados demonstram que o Centro, sem segregação, apresenta as mesmas percepções em relação a a postes sem iluminação que em Nova Viçosa, região mais segregada.

Da mesma forma que anteriormente, $2 \%$ dos domicílios em Nova Viçosa e Centro não possuem iluminação pública na frente do domicílio. Em Santa Clara, por outro lado, todos os chefes de família que foram entrevistados, alegaram possuir, sim, iluminação pública em frente ao domicílio. Quando perguntado ao morador se a iluminação estava funcionando, a resposta mudou. Ou seja, $15 \%$ dos postes de iluminação pública no Centro e 14\% em Nova Viçosa, não estavam funcionando, e apenas $6 \%$ não funcionavam em Santa Clara. Tais dados também demonstram que o centro apresenta até mais deficiência em manutenção da iluminação pública do que os bairros segregados.

Apesar das maiores deficiências em termos de iluminação pública apontadas no Centro e em Nova Viçosa, foram, por outro lado, as regiões onde os moradores relataram maior satisfação em termos de qualidade da iluminação. Tanto Nova Viçosa (66\% dos entrevistados), quanto o Centro (65\% dos entrevistados) relataram que a qualidade da iluminação pública é "boa". Já Santa Clara, mesmo sendo a região, dentre as três que apresentou maior cobertura e funcionamento da iluminação, teve sua qualidade, por outro lado, apontada por $40 \%$ dos entrevistados como "péssima". Ou seja, podemos inferir que a questão da iluminação é um problema generalizado, independente do nível de segregação, uma vez que uma região apresenta boa cobertura de iluminação, mas não apresenta uma boa qualidade de iluminar, e vice-versa. 
Observou-se que em $48 \%$ das casas em Nova Viçosa não há meio fio. Em Santa Clara esses números são menores, pois apenas $11 \%$ das casas não o possuíam. Já na região Centro, 95,5\% dos domicílios possuem o meio fio, ou seja, apenas $4,5 \%$ das residências não o possuem. Para Perroca, Bezerra e Manzato (2018, p.81):

Na maioria dos municípios brasileiros, as legislações municipais definem que as calçadas são de responsabilidade dos proprietários dos lotes adjacentes a elas, mesmo que essas sejam independentes dos lotes. Porém, as calçadas são espaços públicos, parte dos sistemas viários municipais e, como definido na Constituição Federal brasileira, são bens públicos de uso comum da população.

Zattar (2008) diz que há um impasse entre juristas sobre essa responsabilidade, ou seja, para alguns, essa responsabilidade é, sim, dos proprietários do terreno. Para outros, essa medida é inconstitucional, uma vez que as prefeituras estão transferindo a responsabilidade de um espaço que é público.

Com base nesses autores e nos dados da pesquisa, podemos inferir que a ausência de meio fio é um fator que está relacionado à segregação socioespacial, seja no Brasil, seja em Viçosa. Se é de responsabilidade do cidadão, como a maioria das legislações municipais definem, os moradores das regiões Nova Viçosa e Santa Clara apresentaram menor porcentagem de domicílios com meio fio, que pode ser explicado pela escassez de recursos, por parte da família, para essa questão, uma vez que possuem necessidades muito mais urgentes. Caso seja responsabilidade do poder público, podemos inferir que há direcionamento dos recursos públicos para áreas centrais, contribuindo assim para as desigualdades de investimentos intra-urbano e aumento das deficiências em infraestrutura em regiões periféricas (VETTER, MASSENA, 1982; CASTELLS 1983; VILLAÇA, 2001).

Observa-se melhores condições de calçamento nas ruas da região Centro do que nas ruas das regiões Nova Viçosa e Santa Clara: $68 \%$ e 58\%, respectivamente, nessas regiões, apresentavam infraestrutura de pavimentação de ruas em pedra fincada/pedra tosca. Por outro lado, em Nova Viçosa, apenas $7 \%$ das ruas são asfaltadas. Em Santa Clara, esse número chega a $25 \%$ das ruas. Já na região Centro, $44 \%$ das ruas são de asfalto. Segundo a Secretaria de Infraestrutura do Ceará (2019), na Tabela de Custos - Versão 026, que discrimina os valores de investimentos em pavimentações, chega a ser 37 reais mais barato a pavimentação do $\mathrm{m}^{2}$ com pedra fincada/pedra tosca, se comparada à pavimentação por paralelepípedo. Assim, infere-se mais uma vez, de acordo com autores supracitados, o direcionamento dos recursos para áreas centrais.

Da mesma forma, quando se observa as ruas em terra batida, percebe-se também o direcionamento dos recursos públicos para regiões centrais (VETTER, MASSENA, 1982; CASTLLS, 1983; VILLAÇA, 2001). Em Nova Viçosa, 22\% das ruas ainda são de terra batida; em Santa Clara, apenas 3\%; e no Centro, nenhuma rua se encontra nessa situação. Esses dados revelam a precariedade da pavimentação que as duas regiões com maiores índices de segregação socioespacial apresentam atualmente.

Quando questionados sobre a qualidade das ruas de sua região urbana, os chefes de família, tanto de Nova Viçosa quanto de Santa Clara, disseram, em sua maioria, que as ruas são "ruins" ou "péssimas", ou seja, em Nova Viçosa, 68\%, e em Santa Clara, 58\% dos chefes de família, 
criticaram a situação e manutenção das ruas. Na região Centro, de forma contrária, $62 \%$ dos chefes de família relataram que a qualidade da rua está "boa" ou "excelente".

No que se refere ao acesso à rede de água, observa-se que $100 \%$ dos domicílios em todas as três regiões já possuem água tratada pelo SAAE Viçosa. Entretanto, há famílias que ainda não possuem rede de esgoto, caso de $4 \%$ da população de Nova Viçosa e $5 \%$ da população de Santa Clara. A região Centro, por sua vez, não apresenta essa deficiência.

Apesar de todos citarem que há recolhimento do lixo pelo SAAE, muitos moradores de Nova Viçosa reclamaram sobre a quantidade de vezes que é feito o serviço nessa região. Segundo Cruz (2014), o SAAE faz o recolhimento nessa região apenas 3 vezes por semana, sendo a única região urbana de Viçosa que é atendida em quantidade reduzida. As demais regiões urbanas de planejamento de Viçosa recebem o serviço 6 vezes por semana, evidenciando que nessa categoria de análise, também há intervenção do poder público selecionando seus recursos para áreas específicas, caracterizando a situação da coleta de lixo como um fator de segregação socioespacial em na cidade estudada (SINGER, 1979; VILLAÇA,1998).

\section{CONCLUSÕES}

Em linhas gerais, o trabalho buscou descrever três regiões urbanas de planejamento de Viçosa, Minas Gerais, duas delas caracterizadas com os mais altos índices de Segregação Socioespacial e a outra categorizada como não segregada socioespacialmente. A utilização da análise comparativa permitiu entender semelhanças, principalmente entre as duas regiões com alto índice de segregação socioespacial no que diz respeito ao tipo de violência, acessibilidade, falta de investimentos em infraestrutura por parte do poder municipal, e perfil socioeconômico e suas diferenças em relação à região centro, que se mostrou muito mais equipada em termos urbanísticos e características socieconômicas.

As características mais marcantes de locais segregados socioespacialmente são a falta de infraestrutura, o alto índice de violência e os dados socioeconômicos inferiores. $E$ isso foi observado tanto em Nova Viçosa quanto em Santa Clara, seja pela falta de calçamento ou pavimentação, seja pela falta de iluminação pública em várias ruas, seja pelo limitado recolhimento de lixo, seja pela falta de limpeza das ruas ou até mesmo pelo alto índice de homicídio, principalmente em Santa Clara, que registrou 8 homicídios em 2016, sendo o maior de Viçosa (MG) no ano.

Estas características não foram observadas da mesma forma, de acordo com os dados, na região Centro, local onde se observa melhor infraestrutura e dados socioeconômicos. No que se refere à categoria violência, percebe-se maior incidência de outro tipo de violência, que não homicídios, no Centro, caso dos furtos e roubos, que registrou em 2016, $40 \%$ e 24\%, respectivamente, de todas as ocorrências junto à polícia civil de Viçosa.

Observa-se, na percepção dos entrevistados, que o lixo é um problema generalizado. Entretanto, fica evidente, pelos dados da pesquisa, que há, por parte do poder público, um direcionamento de seus recursos para a área central, uma vez que há diferenciação no número de 
coletas semanais para essa região em relação à região periférica, como é o caso de Nova Viçosa, que é contemplado com apenas 3 coletas por semana, frente a 6 coletas realizadas na primeira.

Em suma, conclui-se que, a partir das análises das 4 categorias, o direcionamento dos recursos municipais e a segregação socioespacial, produzem efeitos negativos em todas as categorias de análise, principalmente para as duas regiões com os mais elevados índices de segregação socioespacial, Nova Viçosa e Santa Clara, frente à região Centro.

Além disso, constatando que o poder municipal direciona seus investimentos em áreas centrais da cidade, tal pesquisa abre caminho para pesquisas que busquem entender e relacionar o local segregado socioespacialmente com as redes sociais de apoio que cercam o cotidiano dessas pessoas, buscando revelar as sociabilidades e os apoios que acabam proporcionando suporte a essas famílias que vivem com alto nível de vulnerabilidade, em termos econômicos e sociais, por falta de atuação do poder público municipal.

\section{REFERENCIAS BIBLIOGRÁFICAS}

BASTOS FILHO, R. A; ALMEIDA PINTO, N. M.; CARVALHO FIÚZA, A. L; FAZITO. D. (2019). A elaboração de um índice de segregação socioespacial como ferramenta de gestão e análise do espaço urbano de Viçosa-MG, interações, Campo Grande, MS, v. 20, n. 3, p. 707-723.

BABBIE, E. (1999). Métodos de Pesquisas de Survey. Belo Horizonte: Editora UFMG.

BONDUKI, N. (1998). Origens da habitação social no Brasil. Arquitetura moderna, lei do inquilinato e difusão da casa própria. 3a Ed - São Paulo, Estação Liberdade: FAPESP.

BONDUKI, N. (2010). Uma cidade aberta e segura. Disponível em:

https://www.cartacapital.com.br/sociedade/uma-cidade-aberta-e-segura . Acesso em: 10 ago. 2017.

BONDUKI, N. e ROLNIK, R. (1982). "Periferia da Grande São Paulo: reprodução do espaço como expediente de reprodução da força de trabalho". In: MARICATO, E. (org.). A produção capitalista da casa (e da cidade) do Brasil industrial. São Paulo, Alfa-Ômega. pp. 117-154.

BRASIL. SECRETARIA DE INFRAESTRUTURA DO CEARÁ. Disponível em :

http://sites.seinfra.ce.gov.br/siproce/onerada/html/20.8.html?a=1545419866925 Acesso em: 01 de fev de 2019.

CALDEIRA, T. P. R. (2000). Cidade de muros: crime, segregação e cidadania em São Paulo. São Paulo, Editora 34/Edusp.

CASTELLS, M. (1983). A questão urbana. Rio de Janeiro: Paz e Terra.

CARVALHO C. O; SANTOS L. M. (2017). Cidades do medo: como a geografia da criminalidade e do medo se apresentam na cidade de Vitória da Conquista-BA. In: ADVOCACIA-GERAL DA UNIÃO (Org). Los desafíos jurídicos a la gobernanza global: una perspectiva para los próximos siglos, 1aed, Brasília-DF p. 45. 
CRUZ, T. A. (2014). Retrato social de Viçosa V. Viçosa, MG: CENSUS.

DO LAGO, L. C. (2002). A lógica segregadora na metrópole brasileira: novas teses sobre antigos processos. Planejamento e Território, p. 155.

FLORES, C. (2006). "Consequências da segregação residencial: teoria e métodos”, In: CUNHA, J.M.P. (org.), Novas metrópoles paulistas: população, vulnerabilidade e segregação, Campinas: NEPO/UNICAMP.

FREY, K., DUARTE, F. (2006). Auto-segregação e a gestão das cidades. Revista Ciências Sociais em Perspectiva, v. 5, n. 9.

IBGE. (2015). Pesquisa nacional por amostra de domicílios: síntese de indicadores (PNAD)2013 / IBGE, Coordenação de Trabalho e Rendimento. - 2 ed, Rio de Janeiro: IBGE, 296p. Disponível em: < https://biblioteca.ibge.gov.br/visualizacao/livros/liv94414.pdf> Acesso em: 10 de julho de 2018.

IZUMINO, W. P., NEME, C. (2002). Violência urbana e graves violações de direitos humanos. Ciência e Cultura, v. 54, n. 1, 47-49.

KAZTMAN, R; FILGUEIRA, F. (2006). As normas como bem público e privado: reflexões nas fronteiras do enfoque "ativos, vulnerabilidade e estrutura de oportunidades" (Aveo). In: CUNHA, José Marcos P. da (Org.). Novas metrópoles paulistas: população, vulnerabilidade e segregação. Campinas, SP: Nepo.

LIMA, M. T. (2004, Apr). Criminalidade altera perfil urbano. Cienc. Cult., São Paulo , v. 56, n. 2, p. 08-09.

LOJKINE, J. (1981). O estado capitalista e a questão urbana. São Paulo, Martins Fontes.

MARICATO, E. (1997). Habitação e cidade. Atual Editora. São Paulo..

MARICATO, E. (2000). Urbanismo na periferia do mundo Globalizado. São Paulo em Perspectiva, 14(4).

MARICATO, E. (2013). Ciclo de Debates. Disponivel em:

>http://www.fpabramo.org.br/ciclosfpa/?page_id=60<. Acesso em: 03/05/2016

MATOS, O. N. (1958). de. São Paulo no século XIX. In: AZEVEDO, A., de. A cidade de São Paulo: estudos de geografia urbana.v.2, São Paulo: Ed. Nacional.

PERROCA, N. W. D.; BEZERRA, B. S.; MANZATO, G. G. (2018). Entraves para a acessibilidade nas calçadas-Um estudo exploratório na área urbana de Bauru-SP. Revista dos Transportes Públicos-ANTP-Ano, v. 40, p. 2ㅇ.

PINÇON-CHARLOT, M. et al. (1986). Ségrégation urbaine. Paris, Anthropos.

RODRIGUES DE SOUSA, M. T. (2005). Mobilidade e acessibilidade no espaço urbano. Sociedade \& Natureza, v. 17, n. 33. 
SANTOS, M. (1993). A urbanização brasileira. São Paulo: Hucitec.

SCHAEFFER, M. F. C. (2003). Segregação socioespacial no Distrito Federal. Revista Katálysis, v. 6, n. 2, p. 237-248.

SINGER.P. (1979). O uso do solo na economia capitalista. In: A produção capitalista da casa (e da cidade) no Brasil industrial. Editora Alfa-Omega. São Paulo.

SPOSITO, M. E. B. (2016). Segregação socioespacial e centralidade urbana. A cidade contemporânea: segregação espacial. São Paulo: Contexto, p. 61-93.

TORRES, H.G.; FERREIRA, M.P. E GOMES, S. (2005). “Educação e Segregação Social: Explorando o Efeito das Relações de Vizinhança". In: MARQUES, E. e TORRES, H.G. (eds.), São Paulo: segregação, pobreza e desigualdade, São Paulo: Editora do Senac.

WEISELFISZ, J. J. (2013). Homicídios e juventude no Brasil. Brasília: Secretaria Nacional de Juventude-Presidência da República.

VASCONCELOS, E. A. (2001). Transporte urbano, espaço e equidade - Análise das políticas públicas. São Paulo: Editora Annablume.

VETTER, David; MASSENA, Rosa Maria R. (1982). Quem se apropria dos benefícios líquidos dos investimentos do Estado em infra-estrutura urbana? Uma teoria de causação circular. Silva LAM, organizador. Solo Urbano: tópicos sobre o uso da terra. Rio de Janeiro: Zahar, p. 49-78.

VILLAÇA, F. (1998). A segregação urbana. In: Espaço intra-urbano no Brasil. Studio Nobel. São Paulo.

VILLAÇA, F. (2001). Espaço intra-urbano no Brasil. São Paulo: Studio nobel: FAPESP.

VILLAÇA, F. (2011). São Paulo: segregação urbana e desigualdade. Estudos avançados, v. 25, n. 71, p. 37-58.

ZATTAR, N. (2008). Calçadas: espaços públicos ou privados. Cáceres: Unemat. Disponível em: http://www.revistalinguas.com/edicao23_24/artigo5.html\#_edn1 . Acesso em: fev. 2019. 